\title{
RNA binding protein CUGBP1 mediates the liver metastasis of colorectal cancer by regulating the ErbB signal pathway
}

\author{
Zhi-Peng Qi ${ }^{1,2 \#}$, Zhang-Han Chen ${ }^{1,2 \#}$, Dong-Li He ${ }^{3 \#}$, Shi-Lun Cai ${ }^{1,2}$, Bing $\mathrm{Li}^{1,2}$, Di Sun ${ }^{1,2}$, Zhen-Tao Lv ${ }^{1,2}$, \\ En-Pan Xu ${ }^{1,2}$, Qiang Shi ${ }^{1,2,4}$, Yun-Shi Zhong ${ }^{1,2,4}$, Jian-Min $\mathrm{Xu}^{5}$ \\ ${ }^{1}$ Endoscopy Center, Zhongshan Hospital of Fudan University, Shanghai, China; ${ }^{2}$ Endoscopy Research Institute of Fudan University, Shanghai, \\ China; ${ }^{3}$ Department of Internal Medicine of Xuhui Hospital, Affiliated Zhongshan Hospital, Fudan University, Shanghai, China; ${ }^{4}$ Endoscopy Center \\ of Xuhui Hospital, Affiliated Zhongshan Hospital, Fudan University, Shanghai, China; ${ }^{5}$ General Surgery Department, Zhongshan Hospital, Fudan \\ University, Shanghai, China \\ Contributions: (I) Conception and design: Q Shi, YS Zhong, JM Xu; (II) Administrative support: Q Shi, YS Zhong, JM Xu; (III) Provision of study \\ materials or patients: YS Zhong, JM Xu; (IV) Collection and assembly of data: ZP Qi, ZH Chen, DL He; (V) Data analysis and interpretation: ZP \\ Qi, ZH Chen, DL He; (VI) Manuscript writing: All authors; (VII) Final approval of manuscript: All authors. \\ \#These authors contributed equally to this work. \\ Correspondence to: Jian-Min Xu, MD, PhD. General Surgery Department, Zhongshan Hospital, Fudan University, Shanghai, China. Email: \\ xu.jianmin1@zs-hospital.sh.cn; Yun-Shi Zhong, MD, PhD; Qiang Shi, MD, PhD. Endoscopy Center, Zhongshan Hospital of Fudan University, \\ Shanghai, 200032, China. Email: zhong.yunshi@zs-hospital.sh.cn; shiqiangqy@126.com.
}

Background: The CUGBP1 (CELF1) is differentially expressed in liver metastasis and no liver metastasis colorectal cancers (CRC) tissues and the function of CUGBP1 in CRC is still unclear.

Methods: Five cases of colorectal adenocarcinoma and 6 cases of liver metastatic CRC lesions were collected and subjected to cDNA microarray and bioinformatical analyses. The quantitative reverse transcription-polymerase chain reaction (qRT-PCR) was used to confirm the result. Cell function assays were used to study the function of CUGBP1, and the western blot was used to discover the change of the downstream molecules.

Results: CUGBP1 was significantly elevated in liver metastatic CRC lesions. Besides, the CUGBP1 can promote proliferation, colony formation, invasion, metastasis abilities as well as increase the apoptosis rates of CRC cells. ERBB2 was positively related to the CUGBP1. Western blot results found that silence of CUGBP1 decreased the protein level of p-AKT and p-ERK without influence the expression level of total protein of AKT and ERK.

Conclusions: CUGBP1 can promote liver metastasis of CRC by promoting the phosphorylation of AKT and ERK through the ErbB signaling pathway. CUGBP1 is a potential biomarker for early detection of CRC and maybe a novel therapeutic target of CRC treatment, especially in liver metastasis.

Keywords: Colorectal cancer (CRC); liver metastasis; cDNA microarray; Human CUG-binding protein; ErbB signaling pathway

Submitted Feb 18, 2021. Accepted for publication May 20, 2021.

doi: $10.21037 /$ tcr-21-311

View this article at: https://dx.doi.org/10.21037/tcr-21-311

\section{Introduction}

Nowadays, colorectal cancer (CRC) is one of the most frequently diagnosed cancers worldwide (1). CRC arises as a consequence of the accumulation of genetic alterations and epigenetic alterations that transform colonic epithelial cells into adenocarcinoma cells. Liver metastasis is a common

^ ORCID: 0000-0002-3128-3168. 
metastasis site of CRC and also the main cause of CRC -related mortality (2). Despite extensive research on the biology of cancer progression, the molecular mechanisms involved in CRC metastasis are not well characterized.

Human CUG-binding protein 1 (CUGBP1), also called CELF1 is a member of the CELF family, it plays a pivotal role in cotranscriptional and posttranscriptional RNA processing (3). In recent years, researchers identified that CUGBP1 is a distinct prognostic value in melanoma (4). The CUGBP1 and DEK were early-induced melanoma genes as well as adverse indicators of poor prognosis (4). CUGBP1 has been frequently reported to promote cell proliferation in several tumors. High expression of CUGBP1 can promote glioma cell proliferation and cell cycle process and it was also found to be a novel independent prognostic predictor of glioma patients (5). However, information regarding the functional role of CUGBP1 in CRC is limited. Besides, there are still some studies that found the CUGBP1 may be a tumor suppressor $(6,7)$. Those phenomena indicated that CUGBP1 may have diverse roles in carcinogenesis, which need better elucidated.

In this study, we screened differentially expressed genes in CRC patients with and without liver metastasis. The RNA binding protein CUGBP1 is the most differentially expressed gene between these two groups. Then we silenced the CUGBP1 in DLD-1 and overexpressed the CUGBP1 in SW480. Results from cell function assays revealed that CUGBP1 can promote cell proliferation, the capability of invasion and metastasis as well as the colony-forming ability and inhibit cell apoptosis. Further, the ERBB2 was positively related to the CUGBP1 and the phosphorylation of AKT and ERK was found to be significantly influenced by silencing CUGBP1. We supposed that the CUGBP1 promotes the progression of CRC by promoting the phosphorylation of AKT and ERK through the ErbB signaling pathway. CUGBP1 may be a potential biomarker for early detection of CRC and a novel therapeutic target of CRC treatment. We present the following article in accordance with the MDAR reporting checklist (available at https://dx.doi.org/10.21037/tcr-21-311).

\section{Methods}

\section{Cell culture}

The human CRC cell lines DLD-1 (TCHu134), SW480 (TCHu 172), SW620 (TCHu101), RKO (TCHu116) were obtained from the China Centre for Type Culture
Collection, Chinese Academy of Sciences. HCT116

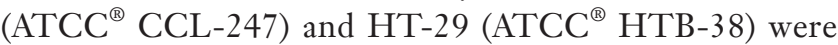
obtained from the American Type Culture Collection. Cells were cultured following the manufacturer's instructions.

\section{Patient's enrollment}

Tumor specimens with clinical and follow-up data were selected from our tumor bank. Patients diagnosed with locally advanced colorectal adenocarcinoma who had no family history of CRC or secondary malignancy and had not received radiation or chemotherapy before surgery were included. Patients in the non-metastatic group had a minimum of 2 years of disease-free survival after surgery. The study was conducted in accordance with the Declaration of Helsinki (as revised in 2013). The study was approved by the ethics committee of Y2017-244 and informed consent was taken from all the patients. 200 CRC patients without chemoradiotherapy were continuously enrolled in a year from Zhongshan hospital for survival analysis. All tissue specimens were immediately taken from the operation room upon excision from the patient, snap-frozen in liquid nitrogen, and then stored at $-80{ }^{\circ} \mathrm{C}$ until use.

\section{$R N A$ extraction and microarray scanning and analysis}

Five cases of CRC with liver metastases and 6 cases of CRC patients were selected to perform gene chip, the basic information was listed in Table 1 and Table 2. Total RNA was extracted using Trizol reagent (Sigma-Aldrich Inc., Germany). mRNA isolation was then carried out using the QIAquick PCR purification Kit (QIAGEN, United States) according to the manufacturer's instruction. The concentration of the total RNA was measured using the spectrophotometer. Next, the mRNAs from CRC lesions were reverse transcribed into cDNA using Cy5-dUTP labeling, while the mRNAs from the normal mucosae were processed with Cy3-dUTP labeling following the manufacturer's protocols (NEN Company, Boston, MA, United States). The labeled probes were then hybridized to the cDNA microarray (Human Genome U133 Plus 2.0 Array, Affymetrix, Inc., United States). Hybridized cDNA microarrays were scanned using Gene PIX 4000 microarray fluorescence scanner (Axon Instruments, Foster City, CA, United States). Accompanying bioinformatical software was used to convert the output images to data form and perform 
Table 1 the general material of the patients doing Gene chip

\begin{tabular}{lccccccc}
\hline Stages & Sex & $\begin{array}{c}\text { Age } \\
\text { (Y) }\end{array}$ & Site & $\begin{array}{c}\text { Maximum } \\
\text { diameter (cm) }\end{array}$ & Pathological type & Differentiation & Stages \\
\hline A & M & 63 & Rectal & 8 & Ulcer type & Medium & T3N1M1 (IV) \\
C & M & 52 & Splenic flexure & 4 & Ulcer type & Medium & T3N1M1 (IV) \\
D & M & 67 & Rectal & 3 & Ulcer type & Medium & T3N2M1 (IV) \\
F & F & 42 & Rectal & 5 & Ulcer type & Medium & T4N1M1 (IV) \\
E & M & 40 & Sigmoid colon & 4 & Ulcer type & Poorly & T4N2M1 (IV) \\
B & M & 54 & Sigmoid colon & 4 & Ulcer type & Medium & T4N0M0 (IIB) \\
H & $M$ & 37 & Ascending colon & 5 & Ulcer type & Medium & T3N0M0 (IIA) \\
I & M & 55 & Rectal & 3 & Ulcer type & Medium & T3N0M0 (IIA) \\
L & $M$ & 64 & Rectal & 5 & Ulcer type & Medium & T4N0M0 (IIB) \\
K & F & 68 & Cecum & 6 & Ulcer type & Medium & T3N0M0 (IIA) \\
J & M & 29 & Ascending colon & 12 & Fungating type & Poorly & T4N0M0 (IIB) \\
\hline
\end{tabular}

Table 2 Classified data of the patients doing gene chip

\begin{tabular}{lcc}
\hline & $\begin{array}{c}\text { Colorectal cancer } \\
\text { with Liver metastasis } \\
\text { (sample) }\end{array}$ & $\begin{array}{c}\text { Colorectal cancer } \\
\text { without Liver } \\
\text { metastasis (control) }\end{array}$ \\
\hline Male & A, C, D & B, H, I, L \\
Female & F & K \\
Low differentiated \\
$\begin{array}{l}\text { adenocarcinoma } \\
\text { group }\end{array}$
\end{tabular}

analysis. Ratios of $\mathrm{Cy} 5: \mathrm{Cy} 3$ was normalized to the median ratio value of all the microarray spots detected. Spots with intensities in both channels that were 0.5 to 2.0 -fold higher than the local background were excluded from further analysis. SPSS 13.0 statistical software (Chicago, IL, United States) was used to carry out Student's t-test statistical analysis. P-values $<0.05$ were considered statistically significant.

\section{Expression and Gene set enrichment analysis (GSEA) analysis}

The Oncomine database was used to scanning the general expression of CUGBP1 in CRC. The UALCAN database was used to evaluate the expression level of CUGBP1 in different nodal metastasis statuses. Gene Set Enrichment
Analysis (GSEA) was performed using the GSEA software v4.0.3 (https://www.gsea-msigdb.org/gsea/index.jsp). The expression level of CUGBP1 was divided into low and high groups based on the median. KEGG gene sets (c2) and ontology gene sets (c5) from MSigDB were used.

\section{Quantitative reverse transcription-polymerase chain reaction ( $q R T-P C R)$}

qRT-PCR was used to detect the CUGBP1 expression level. CUGBP1 mRNA was amplified by real-time PCR with SYBR green (Invitrogen). PCR was initiated by a $15 \mathrm{~s}$ denaturation at $95{ }^{\circ} \mathrm{C}$, followed by 45 cycles of $95{ }^{\circ} \mathrm{C}$ for $5 \mathrm{~s}, 60^{\circ} \mathrm{C}$ for $30 \mathrm{~s}$, using an Applied Biosystems 7900HT Sequence Detection System (Foster City, CA, USA). The internal reference of mRNA was GAPDH. The PCR primers used to amplify the CUGBP1 gene were 5'- ACCTGTTCATCTACCACCTG-3' (forward) and 5'- GGCTTGCTGTCATTCTTCG-3' (reverse). GAPDH (a housekeeping gene) primers were 5'GAAGGTGAAGGTCGGAGTC-3' (forward) and 5'GAAGATGGTGATGGGATTTC-3' (reverse).

\section{Protein extraction and Western blotting}

Total protein was isolated using a lysis buffer containing PMSF and RIPA. For the staining of CUGBP1, an antiCUGBP1 mice polyclonal antibody (sc-20003) was 
purchased from Santa Cruz Biotechnology, Inc. $30 \mu \mathrm{g}$ of protein sample were incubated with denaturing buffer (0.3 M Tris pH 6.8, 10\% 2-mercaptoethanol, $40 \%$ glycerol, $20 \%$ SDS, and $0.02 \%$ bromophenol blue) at $95{ }^{\circ} \mathrm{C}$ for 5 min, loaded onto a $10 \%$ SDS-polyacrylamide gel for electrophoresis, transferred onto PVDF membranes, and then blocked in $5 \%$ non-fat milk/TBS-Tween buffer for $1 \mathrm{~h}$ at room temperature. Membranes were then incubated overnight at $4{ }^{\circ} \mathrm{C}$ in a primary antibody against CUGBP1 (1:500, sc-20003, Santa Cruz), and GAPDH (1:2,000, sc20357, Santa Cruz). ERBB pathway-related antibodies GSK-3 beta (sc-377213), p- GSK-3 beta (sc-373800), ERK1/2 (sc-514302), p-ERK1/2 (sc-81492), AKT1/2/3 (sc-81434), p-Akt1/2/3 (sc-377556). The membranes were then incubated with horseradish peroxidase-conjugated secondary antibodies for $1 \mathrm{~h}$ at room temperature. Immunoreactivity was detected using chemiluminescence (Pierce, Rockford, IL, USA).

\section{Cell transfection with adenovirus vectors}

The siRNA of CUGBP1 was designed and constructed then cloned into the vector pEGFP-N1-3FLAG by repeated excision and ligation successively. The recombinant adenovirus was generated by Genechem CO LTD, Shanghai, China. The particle titers of the adenoviral stocks were $1 \times 10^{9}$ plaque-forming units per milliliter $(\mathrm{pfu} / \mathrm{mL})$. Adenovirus vectors expressing CUGBP1 (Ad-CUGBP1). A green fluorescent protein (Ad-GFP) and negative control (Ad-HK) were used to transfect DLD-1 and SW480 cells. Transfection efficiency was evaluated by testing the expression ratio of the green fluorescent protein. The cells were collected after being transfected for $5 \mathrm{~d}$ as stably transfected cells.

\section{3-(4,5-dimethylthiazol-2-yl)-2,5-diphenyltetrazolium bromide (MTT) assay}

The proliferation of CRC cells was assessed using the MTT assay. Briefly, transfected DLD- 1 or SW480 cells $\left(4 \times 10^{3}\right.$ cells/well) were seeded into 96-well plates and allowed to adhere overnight. At 0 and $24 \mathrm{~h}$, cells in each well were incubated with $20 \mu \mathrm{L}$ of MTT solution $(5 \mathrm{mg} / \mathrm{mL})$ for an additional $2 \mathrm{~h}$ at room temperature. The reaction was stopped by adding $100 \mu \mathrm{L}$ of dimethyl sulfoxide, and the absorbance of each well was measured at $595 \mathrm{~nm}$ using a microplate reader (BioTek Instruments, Inc., USA).

\section{Clone formation assay}

Cells (200 cells per well) were seeded into six-well plates. The plates were incubated for 2 weeks, and colonies were counted with the assistance of a stereomicroscope.

\section{Flow-cytometry analysis}

The apoptosis of CRC cells was determined using flow cytometry. Briefly, transfected DLD-1 or SW480 cells were washed with ice-cold phosphate-buffered saline (PBS) twice and harvested with trypsin. Subsequently, cells were stained with $5 \mu \mathrm{L}$ of Annexin V-FITC/PI (BC, San Jose, CA, USA) in the dark for $30 \mathrm{~min}$. Finally, the apoptosis rate of stained cells was detected using a BD Accuri TM C6 flow cytometer (BD, Franklin Lakes, NJ, USA).

\section{In vitro matrigel invasion assay}

In vitro matrigel invasion assay was performed using a 24-well multicell insert (Corning) with polycarbonate filters (pore size, $8 \mu \mathrm{m}$ ). The upper side of the polycarbonate filter was coated with matrigel $(50 \mu \mathrm{g} / \mathrm{mL}, \mathrm{BD}$ Biosciences). $2 \times 10^{5}$ cells in $200 \mu \mathrm{L}$ of $0.1 \%$ bovine serum albumin serum-free medium were seeded in the upper chamber. The lower chamber was filled with $10 \%$ serum-medium $(700 \mu \mathrm{L})$. Cells were cultured for $24 \mathrm{~h}$ at $37^{\circ} \mathrm{C}$ in $5 \% \mathrm{CO}_{2}$. Cells on the upper surface of the filter were removed using a cotton swab. Chambers were fixed with $4 \%$ neutral-buffered formalin for $30 \mathrm{~min}$ and stained in Giemsa stain for $15 \mathrm{~min}$. The cell number in five fields (up, down, median, left, and right. $\times 200$ ) was counted for each chamber, and the average value was calculated. The invasion rate was calculated by the value of MTT read. The GIEMSA staining of the polycarbonate membrane would be digested with acetic acid. Absorbance values (A) were measured at a wavelength of $490 \mathrm{~nm}$ with a microplate reader.

\section{Statistical analysis}

Statistical analyses were performed using SPSS statistical software (SPSS Inc, Chicago, Illinois). Data were expressed as mean \pm SEM. Statistical significance of differences between groups was performed by One Way Analysis of Variance (ANOVA). P-value $<0.05$ was statistically considered significant. S-N-K was used to analyze the difference between the two groups. All experiments were 
conducted at least three times.

\section{Results}

\section{Expression and Gene set enrichment analysis (GSEA)} analysis

To investigate the role of CUGBP1 in CRC development, we first searched the Oncomine database to examine CUGBP1 expression in CRC tissues. The results found that CUGBP1 was up-regulated in several CRC research (Figure 1A,B,C). The UALCAN database showed that the expression levels of CUGBP1 are significantly different among nodal metastasis statuses (Figure 1D). Further, GSEA analysis found that the high expression of CUGBP1 is closely related to the regulation of autophagy (NES $=2.1550, \mathrm{P}<0.0001)$ and gene silencing $(\mathrm{NES}=2.5018$, $\mathrm{P}<0.0001$ ) (Figure 1E,F).

\section{Validation of CUGBP1 in CRC cells and tissues}

We validated the protein expression of CUGBP 1 in both tissue and CRC cell lines. As shown in Figure 2A,B, CUGBP1 protein was commonly overexpressed (10/12) in CRC tissues and CRC cell lines. IHC results found that the expression of CUGBP1 in the tumor was higher than that in the para tumor (Figure 2C). In total, 200 patients diagnosed with CRC and with no liver metastasis were enrolled to evaluate the relationship between the expression of CUGBP1 and the overall survival rate. The low expression of CUGBP1 in the 93 cases, has a median survival time of 20.9 months, and the high expression of CUGBP1 in the 107 cases, has a median survival time of 18.8 months. The low expression of CUGBP1 is beneficial to the overall survival time of CRC patients $\left(\mathrm{P}=0.049, \chi^{2}=3.686\right)$ (Figure 2D).

\section{Clinicopathological assessment of CUGBP1}

In CRC tissues, the expression of CUGBP1 was found to be significantly up-regulated in the synchronous live metastasis group, compared to the non-liver-metastasis group ( $\mathrm{P}=0.003)$. However, there is no difference between metachronous liver metastasis and synchronous live metastasis, and no difference between the synchronous live metastasis and the non-liver-metastasis group. In normal tissue, the expression of CUGBP1 was up-regulated in the metachronous liver metastasis and the synchronous live metastasis obviously, compared to the non-livermetastasis group $(\mathrm{P}=0.001,0.003)$; there was no obvious difference between the metachronous liver metastasis and the synchronous liver metastasis group. The expression of CUGBP1 was down-regulated $(\mathrm{P}<0.05)$, in each group and CRC tissues than the normal tissues (Table 3). Wilcoxon rank-sum test was applied to analyze the relationship between the CUGBP1 gene expression and clinical cases characterized. In CRC tissues, there was no significant difference between the expression of CUGBP1 and the clinicopathological correlation $(\mathrm{P}>0.05)$. Although in the histological type $\mathrm{P}$ values $<0.05$, considered the imbalance of the number of specimens, the result needed more data to verify (Table 3).

We also applied the chi-square test to analyze the relationship between clinicopathological characteristics and different liver metastasis. At the same time, the incidence of liver metastases and metachronous liver metastasis was related to the depth of invasion $(\mathrm{P}=0.011)$, vascular invasion $(\mathrm{P}=0.009)$, and high CUGBP1 gene expression $(\mathrm{P}=0.003)$; the synchronous live metastasis was related to the depth of invasion $(\mathrm{P}=0.011)$ and CUGBP1 gene expression $(\mathrm{P}<0.001)$ (Table 4); the Logistic multivariate regression analysis (Enter method) shows that: vascular invasion were independent risk factors for metachronous liver metastasis. The depth of invasion (T3-T4) and the CUGBP1 gene expression were independent risk factors for synchronous liver metastasis (Table 5).

Univariate analysis showed that: colorectal liver metastasis prognosis was related to tumor differentiation, lymph node metastasis, vascular invasion, CUGBP1 expression related (Table 6). The univariate analysis, $\mathrm{P}<0.05$ for all the variables included in the multivariate model, derived lymph node metastasis, vascular invasion are independent risk factors for CRC liver metastases prognosis (Table 7).

\section{The silence of CUGBP1 influences the cell cycle, proliferation, and invasion abilities of CRC cells}

Subsequently, we selected DLD-1 cells (with relatively higher CUGBP1 expression) for transfection with siCUGBP1 and SW480 cells (with relatively lower CUGBP1 expression) for transfection with oe-CUGBP1, followed by validation of the transfection efficiency. The results of western blot analysis showed that CUGBP1 expression was remarkably decreased after si-CUGBP1 transfection in DLD-1 cells and upregulated after oe-CUGBP1 
A

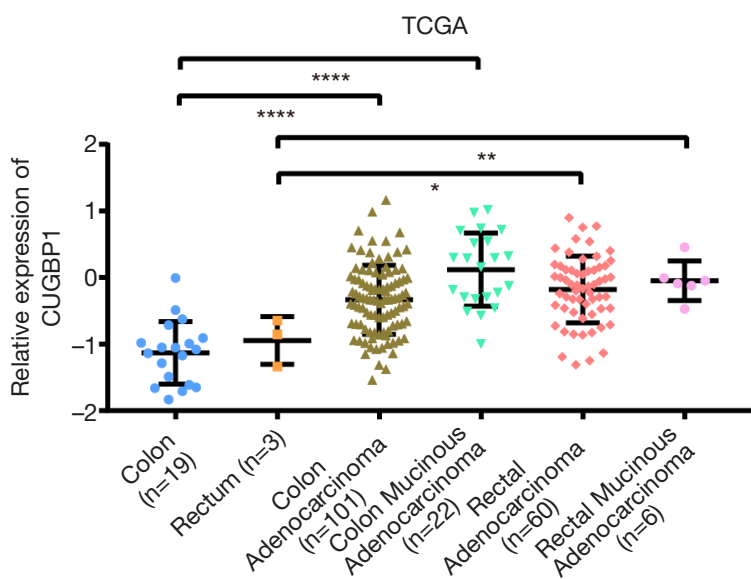

C

$E$

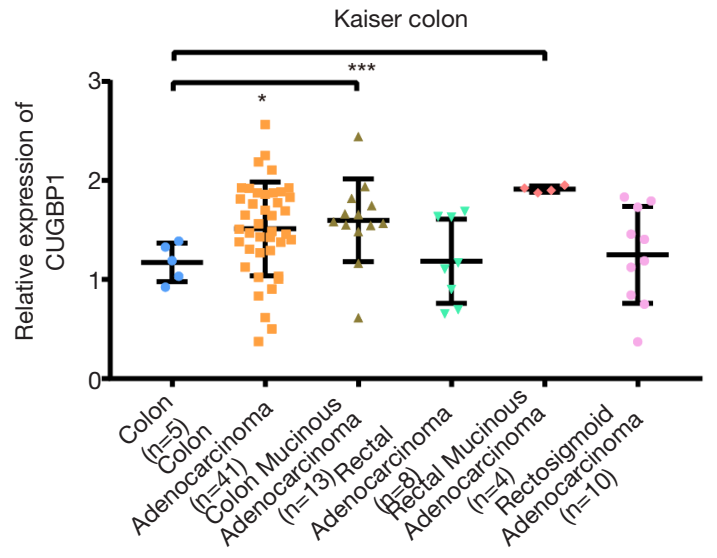

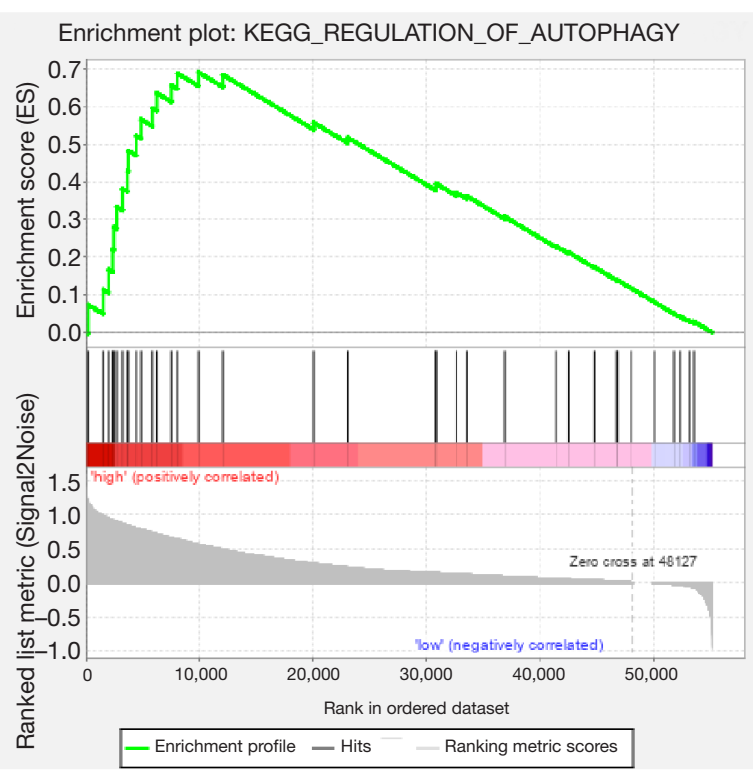

B

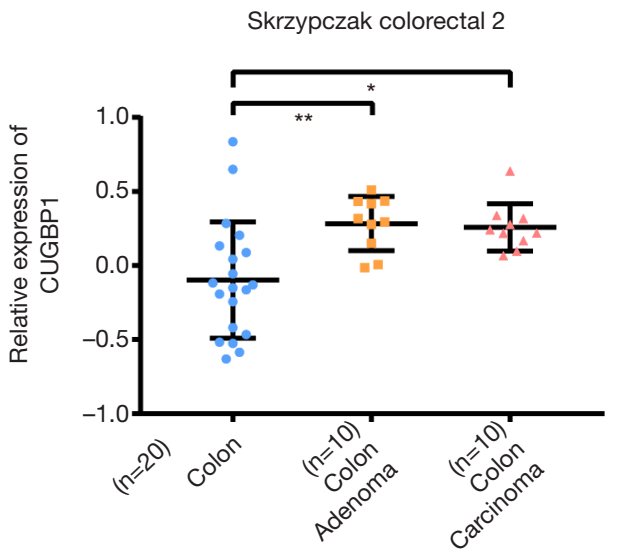

D

Expression in COAD based on nodal metastasis status (TCGA)

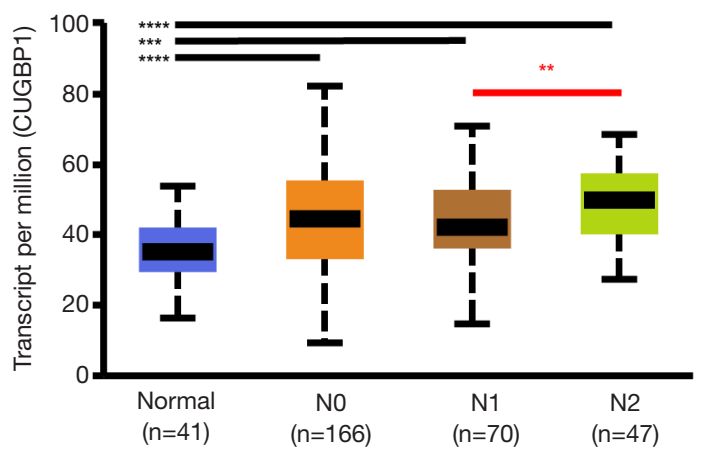

$\mathrm{F}$

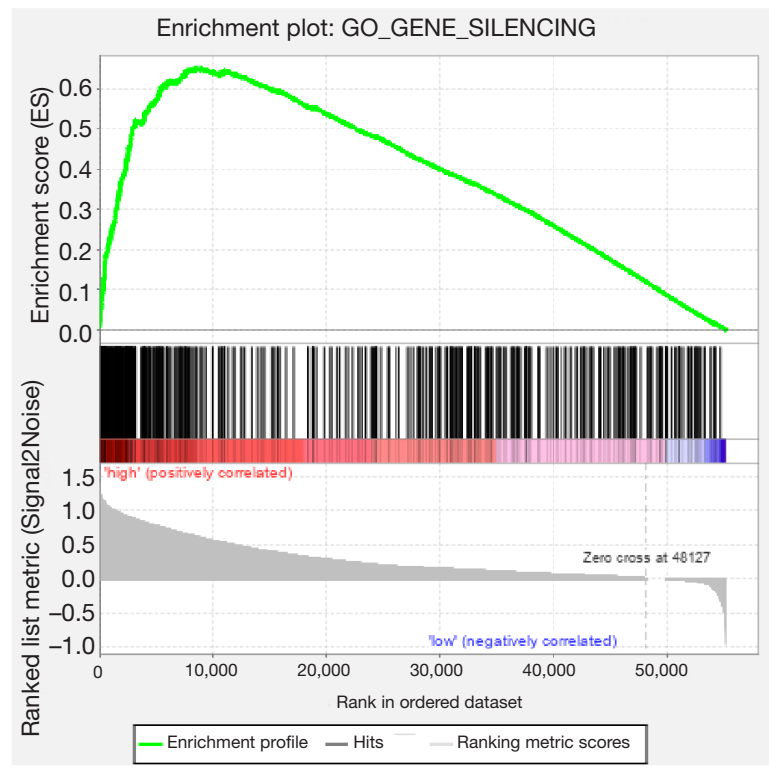

Figure 1 Public databases showed that CUGBP1 is up-regulated in CRC. (A,B,C) Oncomine database showed that CUGBP1 is upregulated in several colorectal cancer research. (D) different levels of CUGBP1 can help to differentiate the nodal metastasis stage. (E,F) GSEA analysis showed that high expression of CUGBP1 is related to the regulation of autophagy and gene silencing. ${ }^{*}, \mathrm{P}<0.05 ;{ }^{* *}, \mathrm{P}<0.01$; ***, $\mathrm{P}<0.001 ;{ }^{* * * *}, \mathrm{P}<0.0001$. 
A

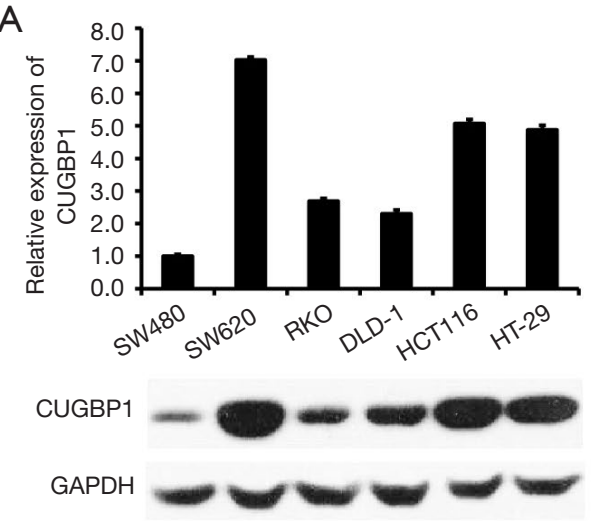

C
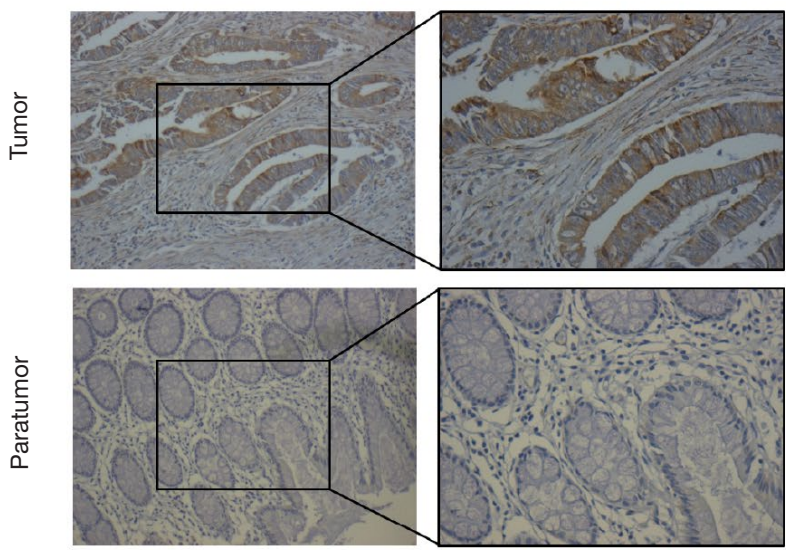

B
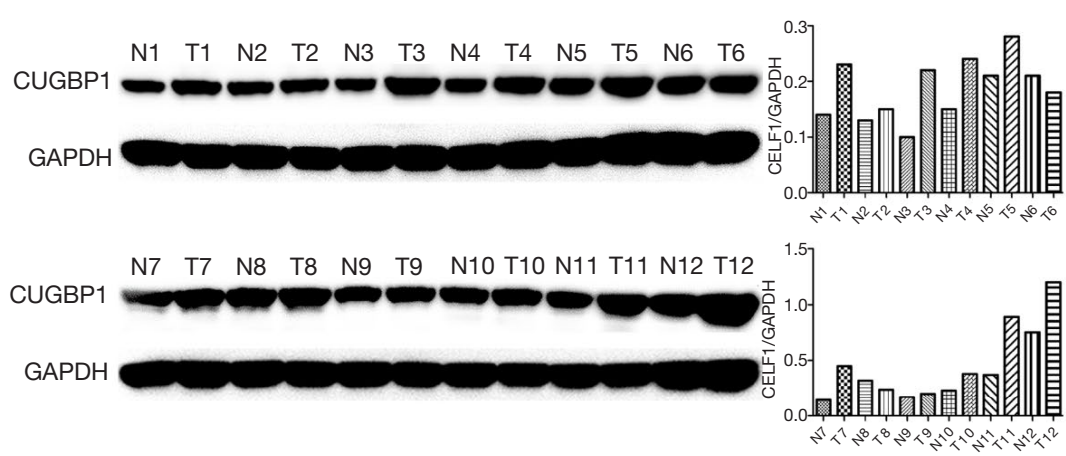

D

Overall survival

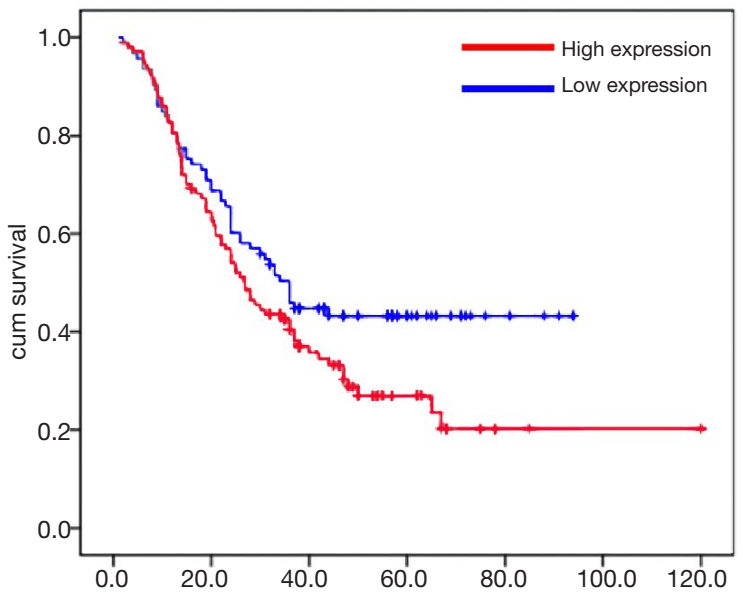

Figure 2 CUGBP1 is up-regulated in CRC cells and tissues. (A) the expression level of CUGBP1 in colorectal cancer cells. (B) the expression level of CUGBP1 in no liver metastasis group, synchronous liver metastasis group, metachronous liver metastasis group, and liver metastasis group. (C) IHC results showed that CUGBP1 is up-regulated in cancer tissue than in para cancer tissue. (D) overall survival analysis found that high expression of CUGBP1 is related to the poor prognosis $(\mathrm{P}=0.049)$.

Table 3 The relationship between the expression of CUGBP1 and the clinical pathology

\begin{tabular}{|c|c|c|c|c|c|}
\hline & \multicolumn{3}{|c|}{ Score } & \multicolumn{2}{|c|}{$\mathrm{P}$} \\
\hline $\begin{array}{l}\text { Metachronous liver } \\
\text { metastasis }\end{array}$ & & 20 & & $0.003^{b}$ & $0.003^{b}$ \\
\hline Synchronous live metastasis & & & 20 & $0.636^{\mathrm{c}}$ & $0.076^{\mathrm{c}}$ \\
\hline \multicolumn{6}{|l|}{ Sex } \\
\hline Male & 13 & 9 & 12 & 0.441 & 0.088 \\
\hline Female & 7 & 11 & 8 & & \\
\hline
\end{tabular}

Table 3 (continued) 
Table 3 (continued)

\begin{tabular}{|c|c|c|c|c|c|}
\hline & \multicolumn{3}{|c|}{ Score } & \multicolumn{2}{|c|}{$\mathrm{P}$} \\
\hline$<62$ & 12 & 11 & 12 & 0.143 & 0.532 \\
\hline$\geq 62$ & 8 & 9 & 8 & & \\
\hline Colon & 15 & 10 & 12 & 0.605 & 0.212 \\
\hline Rectal & 5 & 10 & 8 & & \\
\hline \multicolumn{6}{|l|}{ Size } \\
\hline$<5 \mathrm{~cm}$ & 13 & 15 & 12 & 0.677 & 0.823 \\
\hline Fungating type & 8 & 6 & 7 & 0.875 & 0.878 \\
\hline Ulcer type & 12 & 14 & 13 & & \\
\hline \multicolumn{6}{|l|}{ Histological type } \\
\hline Adenocarcinoma & 18 & 19 & 19 & 0.044 & 0.032 \\
\hline $\begin{array}{l}\text { Mucinous } \\
\text { adenocarcinoma }\end{array}$ & 2 & 1 & 1 & & \\
\hline \multicolumn{6}{|l|}{ Differentiation } \\
\hline I-II & 10 & 10 & 9 & 0.165 & 0.351 \\
\hline \multicolumn{6}{|l|}{ Infiltration depth } \\
\hline$(-)$ & 13 & 13 & 15 & 0.764 & 0.261 \\
\hline$(+)$ & 7 & 7 & 5 & & \\
\hline \multicolumn{6}{|l|}{ Cancerous node } \\
\hline$(-)$ & 14 & 11 & 12 & 0.221 & 0.547 \\
\hline$(+)$ & 6 & 9 & 8 & & \\
\hline \multicolumn{6}{|c|}{$\begin{array}{l}\text { Lymphatic or blood vessel } \\
\text { invasion }\end{array}$} \\
\hline No & 3 & 5 & 3 & 0.051 & 0.053 \\
\hline Yes & 17 & 15 & 17 & & \\
\hline \multicolumn{6}{|l|}{ Perineural invasion } \\
\hline No & 12 & 14 & 11 & 0.421 & 0.572 \\
\hline Yes & 8 & 6 & 9 & & \\
\hline
\end{tabular}

a , colorectal cancer without liver metastasis vs. metachronous liver metastasis; ${ }^{\text {, }}$ colorectal cancer without liver metastasis vs. synchronous live metastasis; ${ }^{c}$, metachronous liver metastasis vs. synchronous live metastasis. 
Table 4 the relationship between clinical-pathological characteristics and liver metastasis

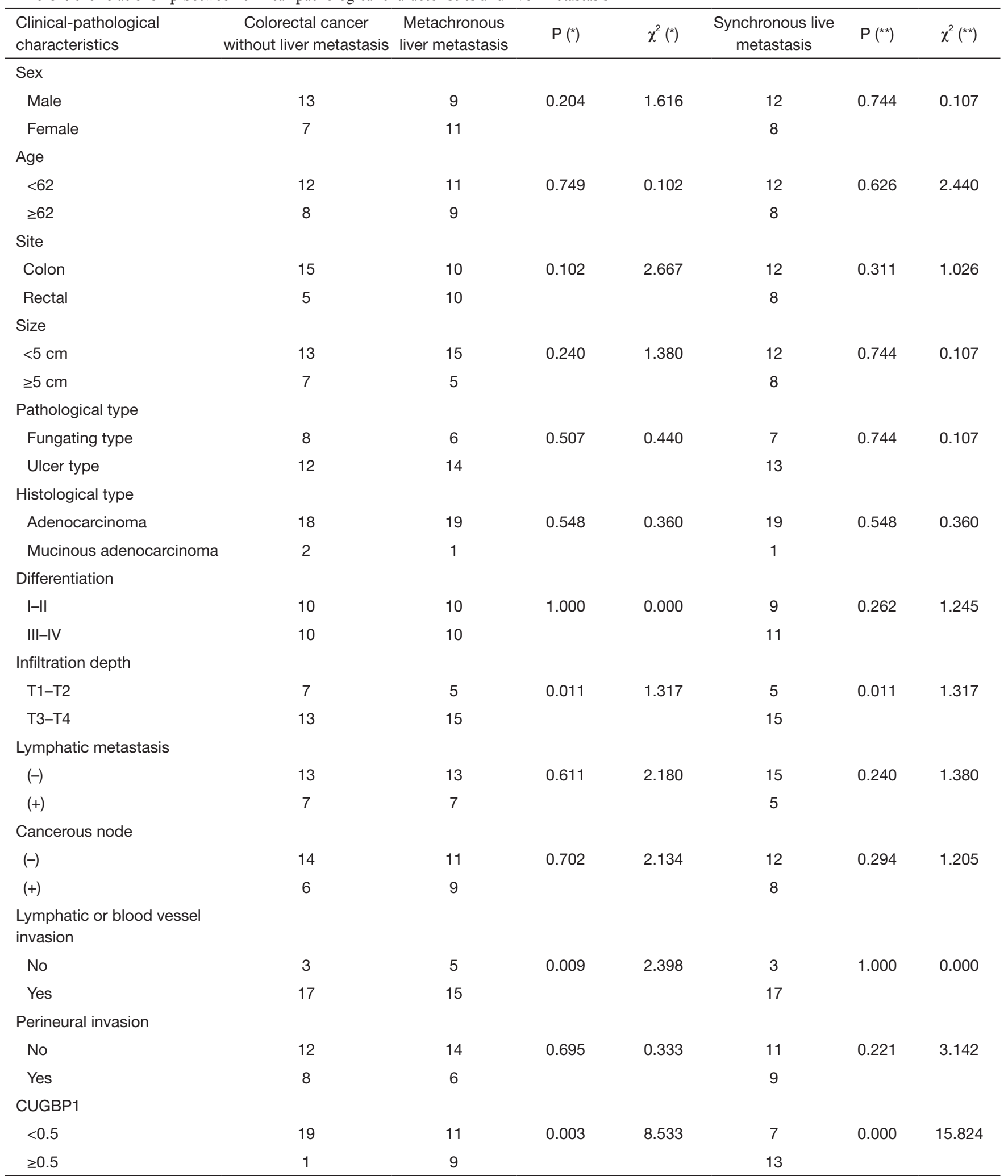

*, colorectal cancer without liver metastasis vs. metachronous liver metastasis; ${ }^{* *}$, colorectal cancer without liver metastasis vs. synchronous live metastasis. 
Table 5 The factor Influence colorectal cancer hepatic metastasis happens.

\begin{tabular}{|c|c|c|c|c|c|c|}
\hline & $\begin{array}{c}\text { Partial regression } \\
\text { coefficient }\end{array}$ & Standard errors & Wald & $\mathrm{P}$ & Relative risks (RRs) & $\begin{array}{l}95 \% \text { confidence } \\
\text { intervals (Cls) }\end{array}$ \\
\hline \multicolumn{7}{|l|}{$\begin{array}{l}\text { Metachronous liver } \\
\text { metastasis }\end{array}$} \\
\hline Infiltration depth & -0.307 & 0.417 & 1.243 & 0.301 & 0.702 & $1.287-1.652$ \\
\hline CUGBP1 & -0.524 & 0.358 & 1.794 & 0.137 & 0.625 & $0.289-0.985$ \\
\hline \multicolumn{7}{|l|}{$\begin{array}{l}\text { Synchronous live } \\
\text { metastasis }\end{array}$} \\
\hline Infiltration depth & -0.940 & 0.401 & 4.804 & 0.042 & 0.399 & $0.191-0.903$ \\
\hline
\end{tabular}

Table 6 The single factor analysis of the colorectal liver metastases survival time

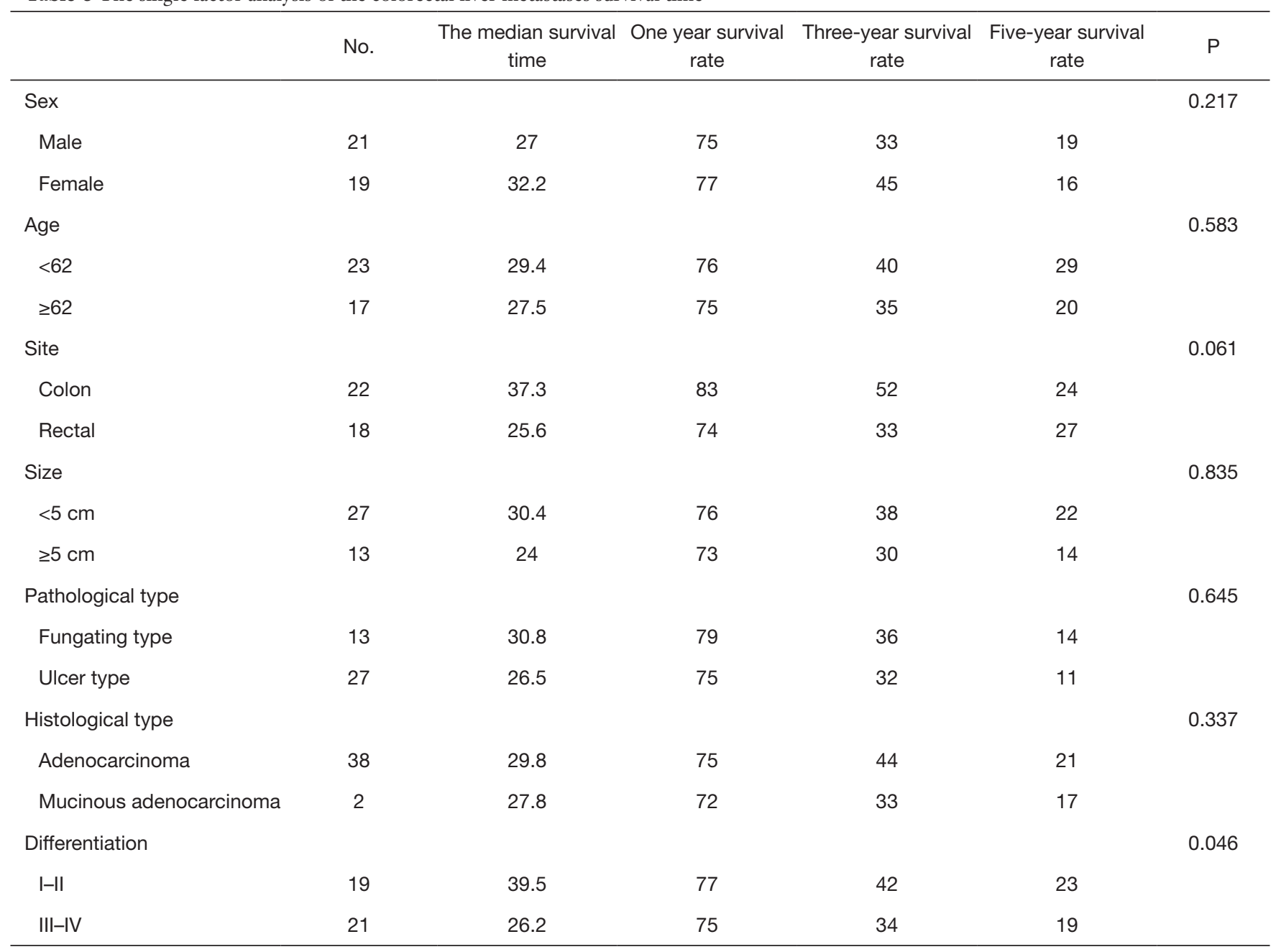

Table 6 (continued) 
Table 6 (continued)

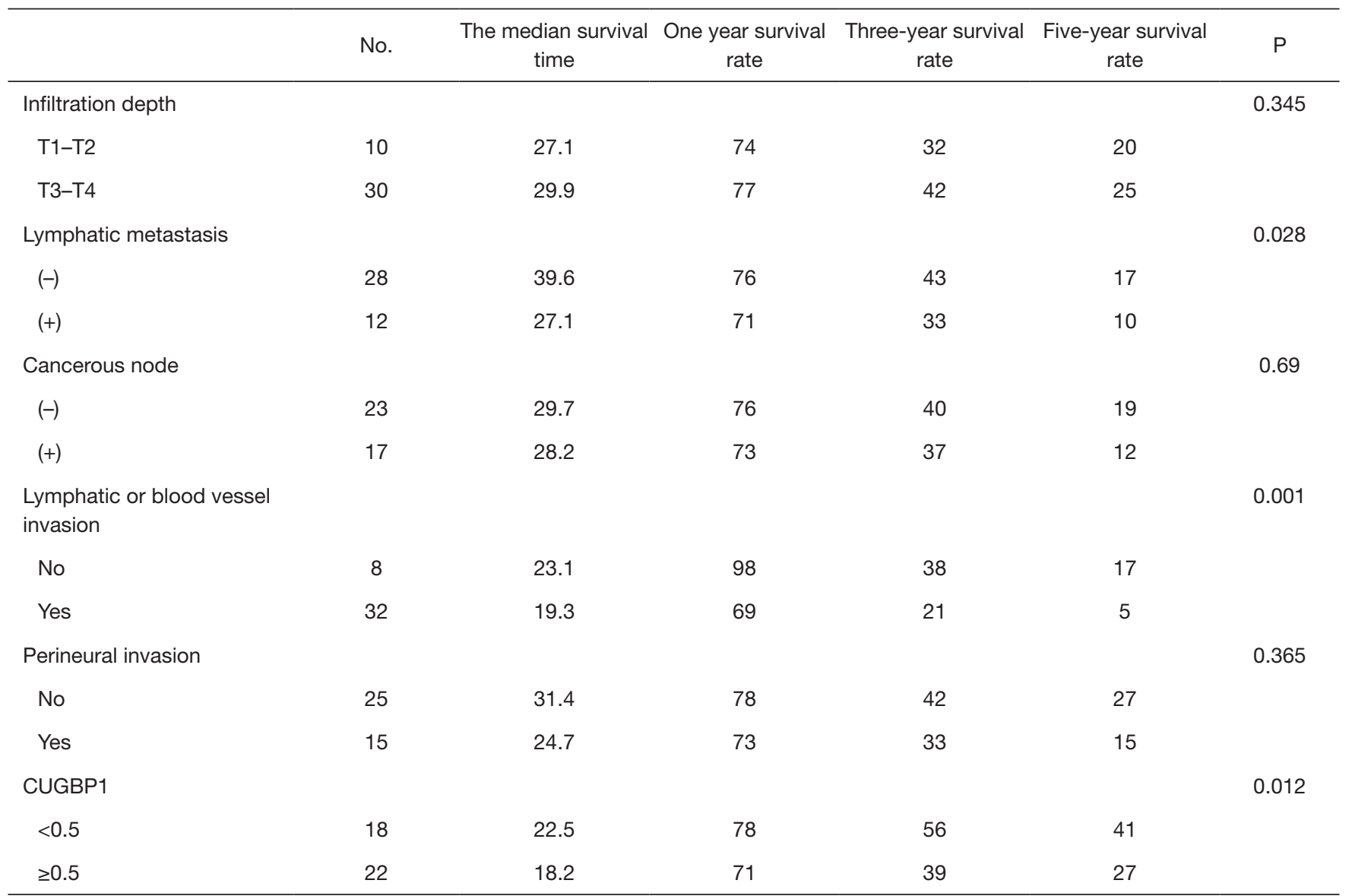

Univariate analysis was calculated using the Kaplan-Meier method (the log-rank test). HR, hazard ratio; Cl, confidence interval; TNM, tumor-node-metastasis.

Table 7 Multivariate analysis of the colorectal liver metastases prognosis.

\begin{tabular}{llr}
\hline Survival time & $\mathrm{P}$ & $\mathrm{HR}(95 \% \mathrm{Cl})$ \\
\hline Differentiation (I/II vs. III/IV) & $\mathrm{NS}$ & $1.921(1.354-2.873)$ \\
Lymphatic metastasis (no vs. yes) & 0.021 & $2.282(1.099-4.452)$ \\
Lymphatic or blood vessel invasion (no vs. yes) & 0.018 & $1.672(1.089-2.385)$ \\
CUGBP1 low expression vs. CUGBP1 high expression & 0.058 & \\
\hline
\end{tabular}

Multivariate analysis was performed using the Cox multivariate proportional hazard regression model with a stepwise method (backward, likelihood ratio). 
transfection in SW480 cells (Figure $3 A, B$ ). In the flow cytometry experiments, the percentages of cells in early and late apoptosis were significantly elevated in DLD1 cells after CUGBP1 knockdown. In contrast, CUGBP1 overexpression notably decreased the apoptosis rate in SW480 cells (Figure 3C). Colony assays showed that the silence of CUGBP1 can weaken the clone formation ability of DLD-1 and SW480 (Figure 3D,E). The MTT assay found that the silence of CUGBP1 can significantly reduce the proliferation ability of DLD-1 and SW480 (Figure 3F). And transwell assays found that the silence of CUGBP1 can weaken the invasion ability of both DLD1 and SW480. These findings suggest that the expression level of CUGBP1 seems to be closely associated with the enhancement of the progression and invasion of DLD-1and SW480 (Figure 3G).

\section{CUGBP1 may influence the cell cycle, apoptosis, and invasion of CRC cells through the ErbB signaling pathway}

Further, based on the COAD dataset from the TCGA database, the expression of CUGBP1 was found positively related to ERBB2 with $\mathrm{R}=0.35(\mathrm{P}<0.001)$ (Figure $4 A$ ). The expression of ERBB2 was evaluated in the CUGBP1 silenced DLD-1 cell, the result also confirmed that both CUGBP1 and ERBB2 were decreased in DLD-1 (Figure 4B). Western blot experiments showed that the silencing of CUGBP1 could significantly inhibit the expression of the phosphorylation of AKT and ERK, which are well-known downstream targets of the ErbB signaling pathway. Meanwhile, the total protein expression levels of AKT and ERK did not change obviously in transfected DLD-1 cells. (Figure 4C,D). The regulation mechanism graph was constructed in Figure 4E.

\section{Conclusions}

CRC is the world's fourth most deadly cancer and caused considerable morbidity and mortality (8). Though numerable treatment options were available, the prognosis of metastasis CRC patients is significantly worse than that of non-metastasis CRC patients (8). Nowadays, much is known about the genes that are affected by cancer-causing mutations in CRC and those clinically relevant biomarkers help to manage the CRC (9), however, less is known about molecular events that are crucial for metastasis formation. The liver is the most common metastasis site of CRC (2). In this study, we explored the mechanism of liver metastasis of
CRC and found that the CUGBP1 plays an important role during the process of liver metastasis.

Primarily, the microarray found a set of 110 genes that can separate metastatic primary tumors from nonmetastatic primary tumors. Of these genes, 60 were up-regulated (55 was known), and 50 were down-regulated (43 was known). Among the differentially expressed genes, CUGBP1 was the only one that was up-regulated in most CRC researches and expressed significantly different among lymph node metastasis statuses. Besides, GSEA analysis found that high expression of CUGBP1 is related to the regulation of autophagy, which is closely related to liver metastasis (10). Human CUG-binding protein 1 (CUGBP1) is one of the key members of the CELF/BRUNOL protein family, whose function in both regulate premRNA alternative splicing and in mRNA editing as well as translation $(11,12)$. Recently, researchers found that CUGBP1 can enhance CRC cells' migration, invasion, and chemoresistance ability by targeting ETS2 (13).

CUGBP1 expression in CRC tissues is higher than in the para cancer tissues. It may relate to the occurrence of CRC and heterochrony liver metastasis. Colorectal carcinoids with low expression of CUGBP1 exhibited no LN metastasis or distant metastasis. Overall survival of patients with high expression of CUGBP1 was poor than that with low expression. However, the survival was similar between carcinoids and adenocarcinomas if the tumors had LN metastasis or distant metastasis. This study also hints that the high expression of CUGBP1 is the independent risk factor of the CRC heterochrony liver metastasis. In terms of cell function assays, the silencing of CUGBP1 can inhibit the proliferation and colony-forming ability of SW480 and DLD-1 cells, and the apoptosis was increased. At the same time, the capability of invasion and metastasis was significantly inhibited, which indicates that the CUGBP1 mediates liver metastasis by promoting the proliferation, invasion, and metastasis ability of CRC. This finding was consistent with the previous researches $(5,14)$. In-depth, we study the downstream regulation mechanism of CUGBP1. Interestingly, the expression of ERBB2 is positively related to CUGBP1. ERBB2 is a member of the epidermal growth factor (EGF) receptor family of receptor tyrosine kinases that are overexpressed in most cancers. It has already been the target of several cancer therapies (15-17). Western blot results showed silence of CUGBP1 can decrease the expression of p-AKT and p-ERK. AKT is a serine/threonine kinase that plays a pivotal role in the PI3K signaling pathway, and it is frequently deregulated in 
A

ò

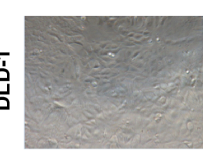

๗

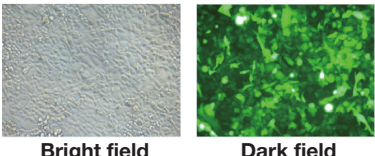

Bright field

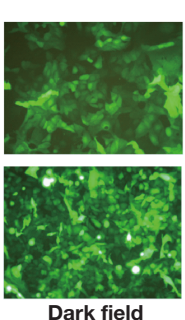

B

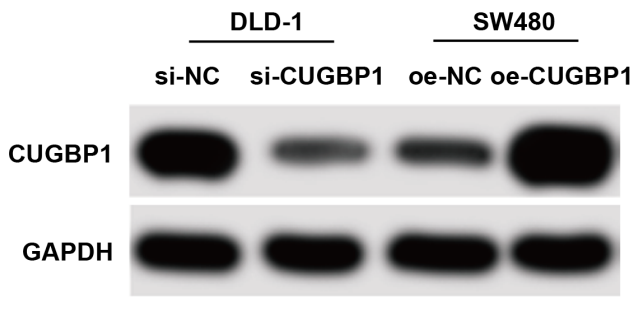

C
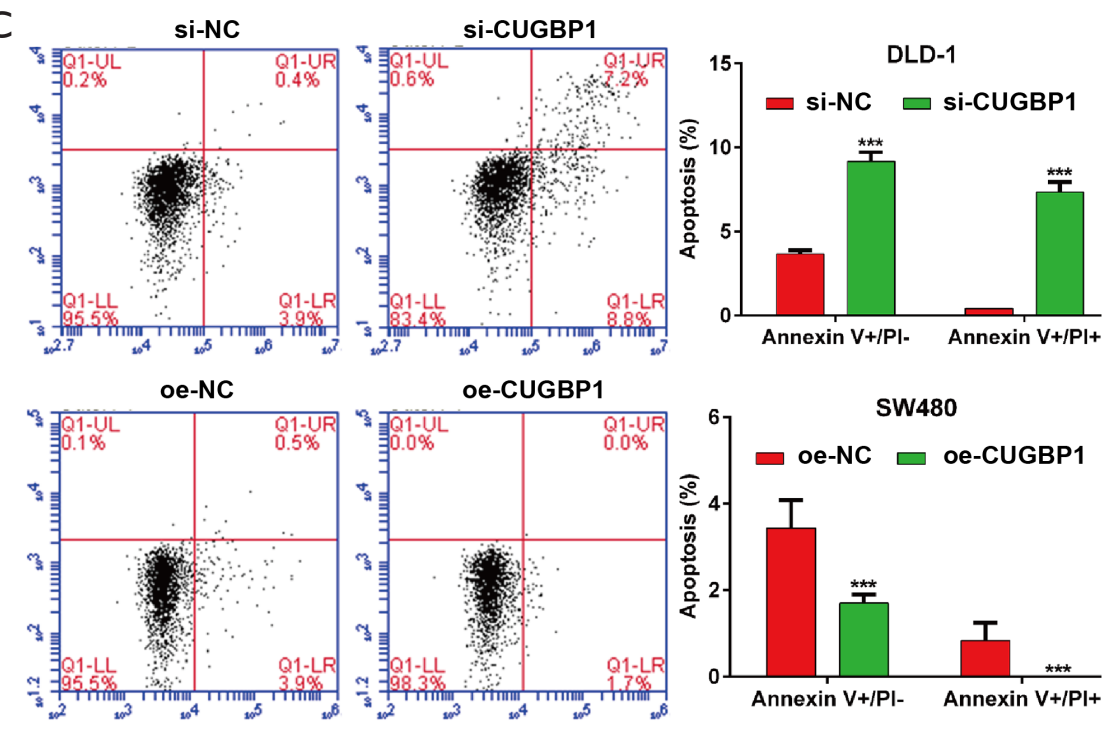

D

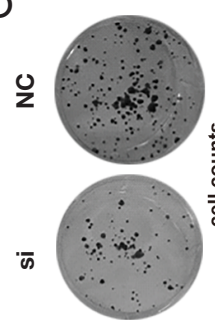

CUGBP1

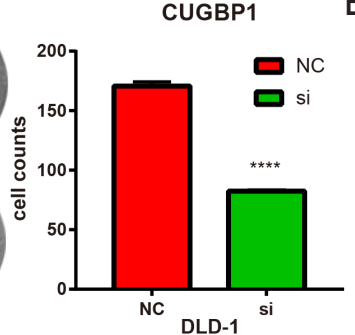

E
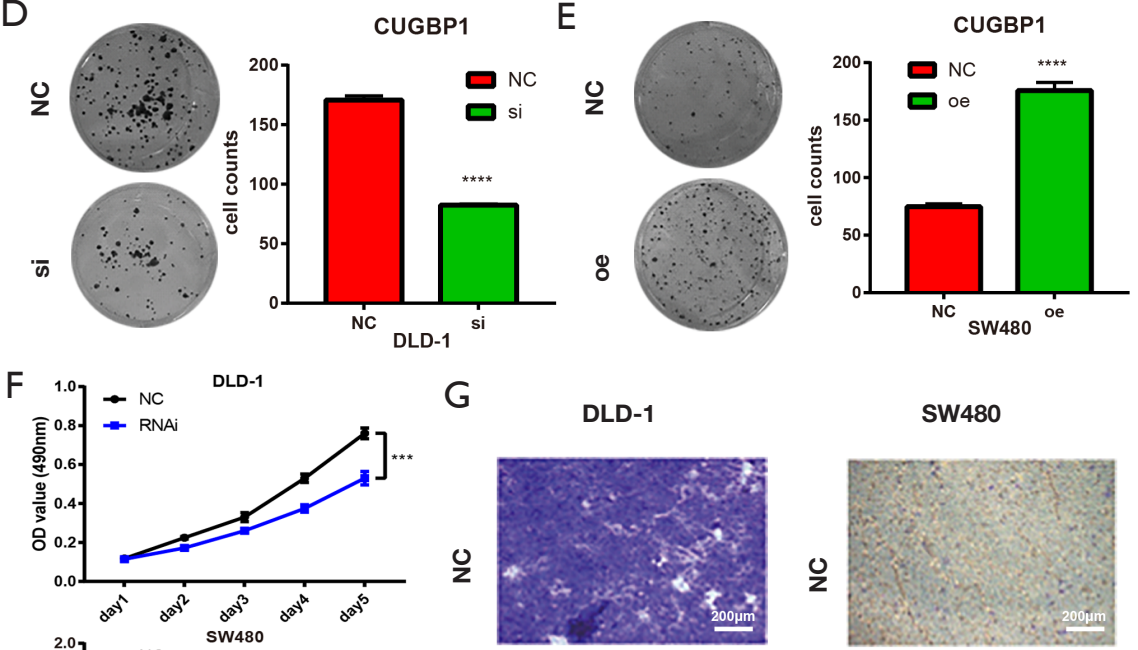

G

DLD-1
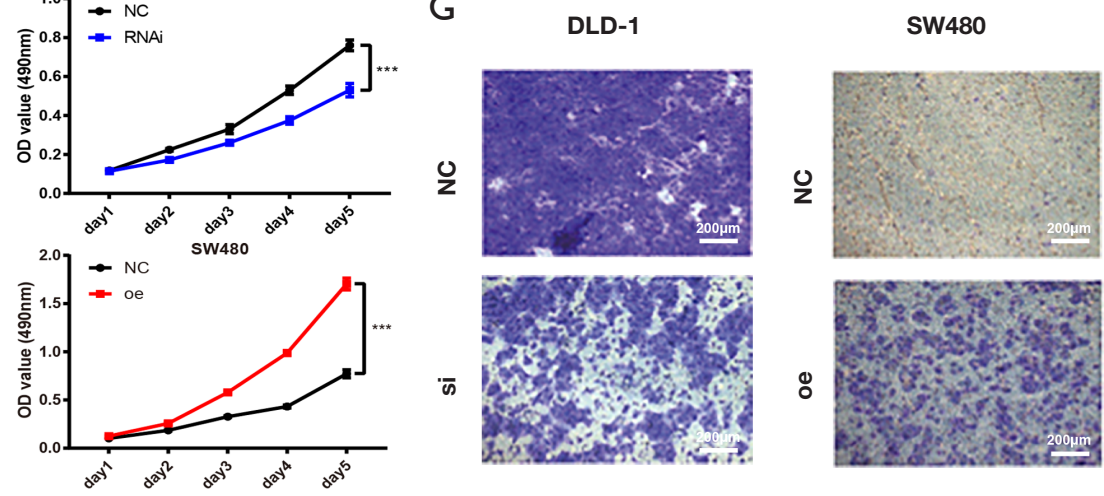

Figure 3 The silencing of CUGBP1 can inhibit the cell cycle, proliferation, and invasion of CRC cells. (A,B) The CUGBP1 was successfully silenced and overexpressed in DLD-1 and SW480. (C) CUGBP1 can inhibit apoptosis. (D,E) CUGBP1 can promote clone formation ability. (F) CUGBP1 can improve the proliferation ability. (G) Giemsa staining showed that CUGBP1 can promote invasion ability $(200 \mu \mathrm{m}) .{ }^{* * *}, \mathrm{P}<0.001 ;{ }^{* * * *}, \mathrm{P}<0.0001$. 
A

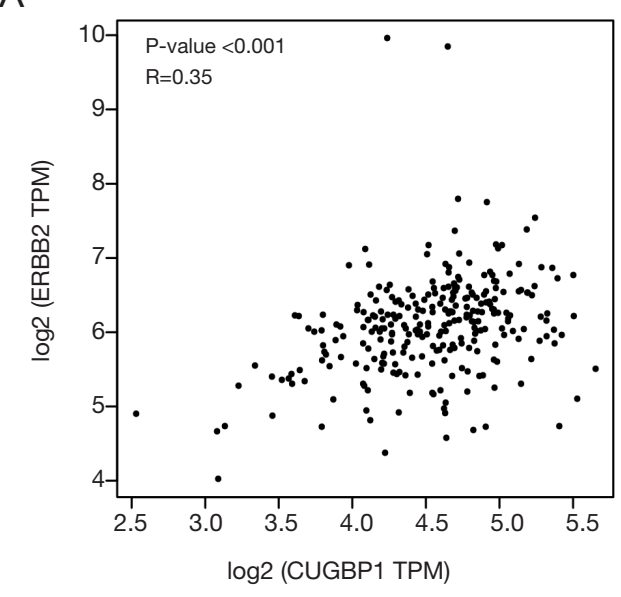

C

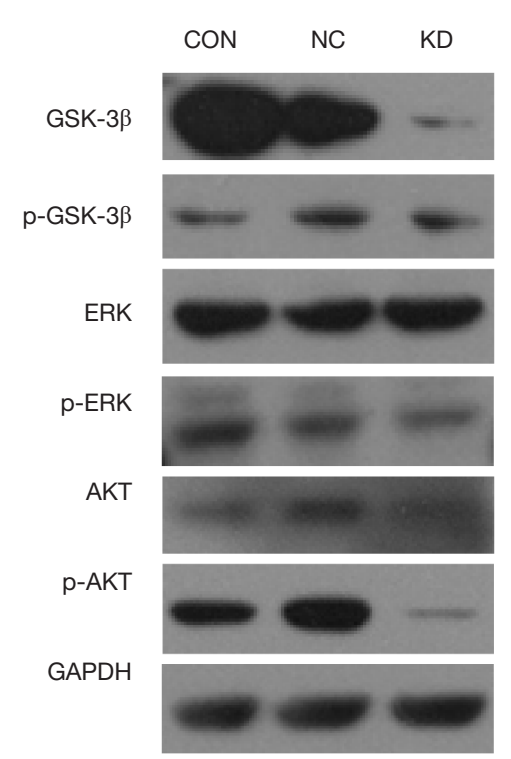

B
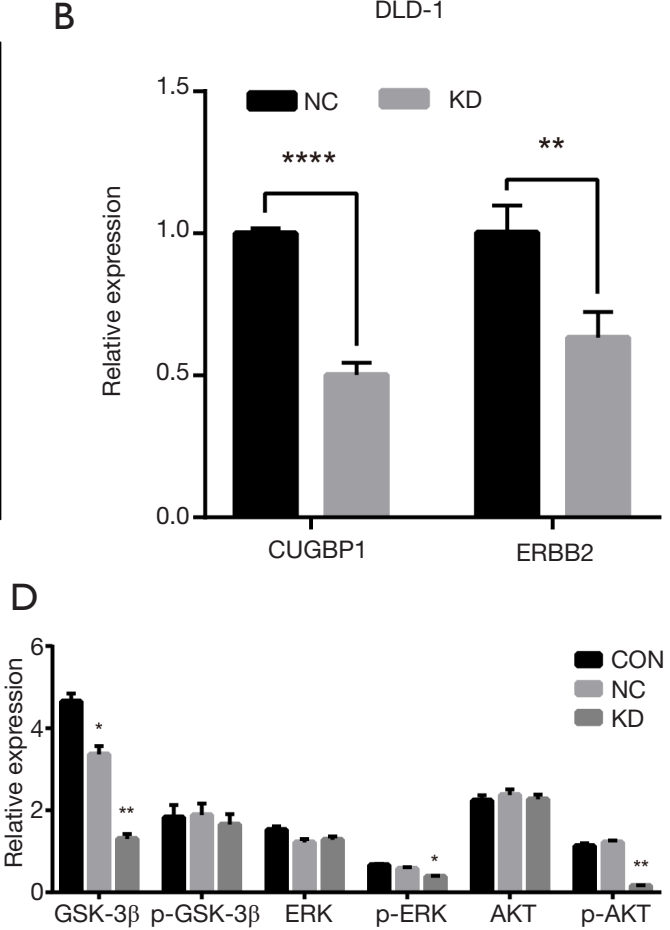

E

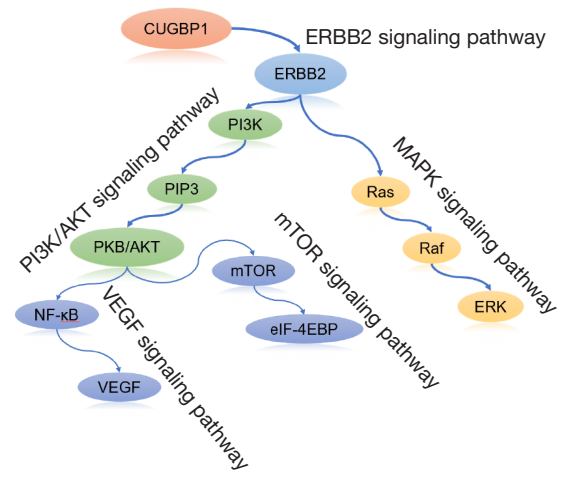

Figure 4 CUGBP1 may influence the progress of CRC through the ErbB signal pathway. (A) The expression of CUGBP1 is positively related to the ERBB2 (based on TCGA cohort). (B) silencing of CUGBP1 resulted in the decrease of ERBB2. (C) silencing of CUGBP1 decreased the expression of the phosphorylation of AKT and ERK without changing their total protein expression. (D) Gray value analysis of the Western blot bands. E: CUGBP1 may mediate the liver metastasis of colorectal cancer by regulating the PI3K/AKT and MAPK signaling pathway through the ErbB signaling pathway. *, $\mathrm{P}<0.05$; **, $\mathrm{P}<0.01$; ****, $\mathrm{P}<0.0001$.

human cancers (18). Studies found that ERBB2 can activate both the Ras/MAPK and PI3K/AKT signal pathway, which plays an important role in the progression and prognosis of cancers $(19,20)$, especially in cell invasion and migration $(21,22)$. Thus, CUGBP1 may promote liver metastasis of CRC by activating MAPK and PI3K pathways through the ErbB2 receptor. ERK1/2 is a member of the MAP kinase family that plays an important role in tumor proliferation, invasion, and metastasis (23). Elevated levels of p-AKT (24-26) and p-ERK (27) have been frequently detected in cancers. In a word, based on the positive effects of p-AKT and p-ERK on the proliferation of CRC cells, we supposed that CUGBP1 can promote CRC growth by upregulating the ErbB signal pathway. 


\section{Acknowledgments}

We would like to thank Dr Bashwin-Hanssa Summah for meticulously polishing our paper.

Funding: This work was supported by the National Key R\&D Program of China (No. 2018YFC1315000/2018YFC1315005, 2019YFC1315800/2019YFC1315802), National Natural Science Foundation of China (No. 81902394, 82002515, 81502000), Shanghai Sailing Program (No.20YF1407200), China Postdoctoral Science Foundation (No. 2020M681177), and Shanghai Municipal Commission of Science and Technology (NO. 19140901902).

\section{Footnote}

Reporting Checklist: The authors have completed the MDAR reporting checklist. Available at https://dx.doi. org/10.21037/tcr-21-311

Data Sharing Statement: Available at https://dx.doi. org/10.21037/tcr-21-311

Conflicts of Interest: All authors have completed the ICMJE uniform disclosure form (available at https://dx.doi. org/10.21037/tcr-21-311). The authors have no conflicts of interest to declare.

Ethical Statement: The authors are accountable for all aspects of the work in ensuring that questions related to the accuracy or integrity of any part of the work are appropriately investigated and resolved. The study was conducted in accordance with the Declaration of Helsinki (as revised in 2013). The study was approved by the ethics committee of Y2017-244 and informed consent was taken from all the patients.

Open Access Statement: This is an Open Access article distributed in accordance with the Creative Commons Attribution-NonCommercial-NoDerivs 4.0 International License (CC BY-NC-ND 4.0), which permits the noncommercial replication and distribution of the article with the strict proviso that no changes or edits are made and the original work is properly cited (including links to both the formal publication through the relevant DOI and the license). See: https://creativecommons.org/licenses/by-nc-nd/4.0/.

\section{References}

1. Siegel RL, Miller KD, Jemal A. Cancer statistics, 2019.
CA Cancer J Clin 2019;69:7-34.

2. Fong Y. Surgical therapy of hepatic colorectal metastasis. CA Cancer J Clin 1999;49:231-55.

3. Wang GS, Kearney DL, De Biasi M, et al. Elevation of RNA-binding protein CUGBP1 is an early event in an inducible heart-specific mouse model of myotonic dystrophy. J Clin Invest 2007;117:2802-11.

4. Cifdaloz M, Osterloh L, Graña O, et al. Systems analysis identifies melanoma-enriched pro-oncogenic networks controlled by the RNA binding protein CELF1. Nat Commun 2017;8:2249.

5. Xia L, Sun C, Li Q, et al. CELF1 is Up-Regulated in Glioma and Promotes Glioma Cell Proliferation by Suppression of CDKN1B. Int J Biol Sci 2015;11:1314-24.

6. Lewis K, Valanejad L, Cast A, et al. RNA Binding Protein CUGBP1 Inhibits Liver Cancer in a PhosphorylationDependent Manner. Mol Cell Biol. 2017;37:e00128-17.

7. Liu L, Ouyang M, Rao JN, et al. Competition between RNA-binding proteins CELF1 and HuR modulates MYC translation and intestinal epithelium renewal. Mol Biol Cell 2015;26:1797-810.

8. Dekker E, Tanis PJ, Vleugels JLA, et al. Colorectal cancer. Lancet 2019;394:1467-80.

9. Sveen A, Kopetz S, Lothe RA. Biomarker-guided therapy for colorectal cancer: strength in complexity. Nat Rev Clin Oncol 2020;17:11-32.

10. Mowers EE, Sharifi MN, Macleod KF. Autophagy in cancer metastasis. Oncogene 2017;36:1619-30.

11. Wagnon JL, Briese $M$, Sun W, et al. CELF4 regulates translation and local abundance of a vast set of mRNAs, including genes associated with regulation of synaptic function. PLoS Genet 2012;8:e1003067.

12. Teplova M, Song J, Gaw HY, et al. Structural insights into RNA recognition by the alternate-splicing regulator CUG-binding protein 1. Structure 2010;18:1364-77.

13. Wang H, Huang R, Guo W, et al. RNA-binding protein CELF1 enhances cell migration, invasion, and chemoresistance by targeting ETS2 in colorectal cancer. Clin Sci (Lond) 2020;134:1973-90.

14. Talwar S, Balasubramanian S, Sundaramurthy S, et al. Overexpression of RNA-binding protein CELF1 prevents apoptosis and destabilizes pro-apoptotic mRNAs in oral cancer cells. RNA Biol 2013;10:277-86.

15. Roskoski R, Jr. The ErbB/HER family of protein-tyrosine kinases and cancer. Pharmacol Res 2014;79:34-74.

16. Arteaga CL, Engelman JA. ERBB receptors: from oncogene discovery to basic science to mechanism-based cancer therapeutics. Cancer Cell 2014;25:282-303. 
17. Zhang H, Berezov A, Wang Q, et al. ErbB receptors: from oncogenes to targeted cancer therapies. J Clin Invest 2007;117:2051-8.

18. Revathidevi S, Munirajan AK. Akt in cancer: Mediator and more. Semin Cancer Biol 2019;59:80-91.

19. Olayioye MA, Neve RM, Lane HA, et al. The ErbB signaling network: receptor heterodimerization in development and cancer. Embo j 2000;19:3159-67.

20. Riese DJ, 2nd, Stern DF. Specificity within the EGF family/ErbB receptor family signaling network. Bioessays 1998;20:41-8.

21. Spencer KS, Graus-Porta D, Leng J, et al. ErbB2 is necessary for induction of carcinoma cell invasion by ErbB family receptor tyrosine kinases. J Cell Biol 2000;148:385-97.

22. Adam L, Vadlamudi R, Kondapaka SB, et al. Heregulin regulates cytoskeletal reorganization and cell migration through the p21-activated kinase-1 via phosphatidylinositol-3 kinase. J Biol Chem 1998;273:28238-46.

Cite this article as: Qi ZP, Chen ZH, He DL, Cai SL, Li B, Sun D, Lv ZT, Xu EP, Shi Q, Zhong YS, Xu JM. RNA binding protein CUGBP1 mediates the liver metastasis of colorectal cancer by regulating the ErbB signal pathway. Transl Cancer Res 2021;10(7):3373-3388. doi: 10.21037/tcr-21-311
23. Fang JY, Richardson BC. The MAPK signalling pathways and colorectal cancer. Lancet Oncol 2005;6:322-7.

24. Wang J, Zhang Y, Liu L, et al. NFAT2 overexpression suppresses the malignancy of hepatocellular carcinoma through inducing Egr2 expression. BMC Cancer 2020;20:966.

25. Man GCW, Wang J, Song Y, et al. Therapeutic potential of a novel prodrug of green tea extract in induction of apoptosis via ERK/JNK and Akt signaling pathway in human endometrial cancer. BMC Cancer 2020;20:964.

26. Mamo M, Ye IC, DiGiacomo JW, et al. Hypoxia alters the response to anti-EGFR therapy by regulating EGFR expression and downstream signaling in a DNA methylation-specific and HIF-dependent manner. Cancer Res 2020;80:4998-5010.

27. Corn BW, Kovner F, Bek S, et al. ERK signaling in colorectal cancer: a preliminary report on the expression of phosphorylated ERK and the effects of radiation therapy. Am J Clin Oncol 2008;31:255-8. 